\title{
Serum calprotectin and ischemia modified albumin levels as markers of disease activity in Behçet's disease
}

\author{
Ahmet Omma ${ }^{1}$, Sevinc Can Sandikci' ${ }^{1}$, Seda Colak ${ }^{1}$, Duygu Tecer ${ }^{2}$, Cigdem Yucel ${ }^{3}$, Zeynep Ozbalkan ${ }^{1}$ \\ ${ }^{1}$ Department of Rheumatology, Ankara Numune Training and Research Hospital, Ankara, Turkey \\ 2Department of Rheumatology, Şanlıurfa Mehmet Akif İnan Training and Research Hospital, Şanlıurfa, Turkey \\ ${ }^{3}$ Department of Clinical Biochemistry, Ankara Numune Training and Research Hospital, Ankara, Turkey \\ Adv Dermatol Allergol 2018; XXXV (6): 609-613 \\ DOI: https://doi.org/10.5114/pdia.2017.71269
}

\begin{abstract}
Introduction: Behçet's disease (BD) is a complex multisystemic inflammatory disorder which is characterized by recurrent attacks of acute inflammation. As there is no universally recognized pathognomonic laboratory marker of $\mathrm{BD}$, its diagnosis is still based on clinical findings.

Aim: To evaluate the role of calprotectin and ischemia modified albumin (IMA) as biomarkers in the assessment of disease activity of BD.

Material and methods: A total of 93 patients with $\mathrm{BD}$ and 62 age- and gender-matched healthy controls were included in the study. Disease activity was assessed with the BD Current Activity Form (BDCAF) score. Serum levels of calprotectin, high-sensitivity C-reactive protein (hSCRP) and IMA were measured in the patient and control groups. Results: Serum levels of calprotectin, IMA and hsCRP in patients with BD were higher than those of the healthy control group ( $p<0.001$ for all). No correlations between calprotectin and IMA, hsCRP, erythrocyte sedimentation rate, CRP, or BDCAF score were found.

Conclusions: As the calprotectin level are increased in BD patients, it could be a candidate biomarker which plays a role in $\mathrm{BD}$ pathogenesis.
\end{abstract}

Key words: calprotectin, ischemia modified albumin, Behçet's disease, disease activity.

\section{Introduction}

Behçet's disease (BD) is a complex multisystemic inflammatory disorder which is characterized by recurrent attacks of acute inflammation [1]. Due to the lack of universally recognized pathognomonic laboratory, radiological, or histological findings of BD, diagnosis is still based on clinical findings [2]. The exact mechanism involved in the pathogenesis of BD remains unknown. Both innate and adaptive immune systems are activated in BD. Hyperactivity of neutrophils, and dysfunction and activation of endothelial cells play an important role in the pathogenesis of BD $[3,4]$. Although many cytokines and biomarkers have been identified to diagnose and monitor disease activity in $\mathrm{BD}$, they are not routinely used in daily practice [5-12].

Calprotectin, also known as MRP-8/MRP-14 or S100A8/A9, is a non-covalently associated heterocomplex of two $\mathrm{S} 100$ calcium binding proteins: myeloidrelated protein 8 (MRP-8 or S100A8) and MRP-14 (or
S100A9) [13]. After release of calprotectin from neutrophils or monocytes, it exerts pro-inflammatory effects mostly via binding to Toll-like receptor 4 (TLR4) and the receptor of advanced glycation endproducts (RAGE) [14]. Under specific conditions, calprotectin can be expressed and secreted from endothelial cells, keratinocytes, osteoclasts, chondrocytes, and fibroblast-like synoviocytes [15]. Although the involvement of S100A8 and S100A9 in the inflammatory process was demonstrated almost 20 years ago, its role in the pathogenesis of rheumatic diseases has only gained great attention in recent years [15]. It has been suggested that calprotectin has a significant correlation with disease activity in patients with rheumatoid arthritis, Still's disease, ankylosing spondylitis, psoriatic arthritis, primary Sjögren's syndrome, systemic lupus erythematosus and pediatric rheumatic disease [16-22]. Elevated serum levels of calprotectin have also been observed in patients with BD. However, no correlation has been found with $C$-reactive protein

Address for correspondence: Ahmet Omma MD, Department of Rheumatology, Ankara Numune Training and Research Hospital, 06230 Ankara, Turkey, phone: +90 505265 1083, fax: +90 31231034 60, e-mail: ahmetomma@hotmail.com Received: 3.10.2017, accepted: 16.10.2017. 
(CRP) levels, erythrocyte sedimentation rate (ESR), white blood cell count, disease activity scores, quality of life, depression or anxiety [23].

Ischemia modified albumin (IMA) is a relatively new biomarker of oxidative stress, and is generated as a result of changes in albumin capacity to bind heavy metals such as cobalt and nickel $[24,25]$. It has been studied in different types of rheumatic diseases [26-29]. Increased serum levels of IMA have been observed in active periods of $\mathrm{BD}$ compared to inactive periods and healthy controls [30-32].

\section{Aim}

The objective of this study was to evaluate the potential use of calprotectin and IMA as biomarkers in assessing disease activity of BD.

\section{Material and methods}

\section{Study population}

A total of 93 patients with BD according to the International Study Group criteria [33] and 62 age- and gender-matched healthy control subjects were included.

Patients and control group subjects were excluded if they had one of the following combined diseases/situations: 1) concomitant autoimmune or autoinflammatory disease; 2) acute or chronic infection; 3) malignancy; 4) systemic disease such as diabetes mellitus or heart failure; 5) pregnancy or up to 6 months postpartum.

The demographic features and clinical characteristics were recorded. Disease activity was assessed with the Turkish version of the BD Current Activity Form (BDCAF) [34]. The BDCAF evaluates clinical features present during the last 4 weeks prior to the date of assessment, and has been shown to have good interobserver reliability for the assessment of general disease activity [35]. The items of this activity form are as follows: headache, oral ulcers, genital ulcers, erythema, skin pustules, arthralgia, arthritis, intestinal involvement, new eye involvement, new nervous system involvement, new major vessel involvement. The BDCAF score was calculated by adding up the scores of each item, giving a total score in the range of $0-12$. The study protocol was approved by the Local Ethics Committee. The research protocol complies with the 2000 Declaration of Helsinki and written informed consent was obtained from all participants.

\section{Laboratory analysis}

Venous blood samples were collected from the participants after $12 \mathrm{~h}$ of fasting. Blood samples collected for analysis were centrifuged at $4000 \mathrm{rpm}$ for $10 \mathrm{~min}$. The separated sera were then aliquoted into Eppendorf tubes and stored at $-80^{\circ} \mathrm{C}$ until the time of analysis.
The serum levels of calprotectin were detected with a commercial calprotectin ELISA (double antibody sandwich ELISA method) test kit (Hycult Biotech Inc, USA) according to the manufacturer's protocol. The high-sensitivity C-reactive protein (hSCRP) and albumin values were detected with the immunoturbidimetric method (values in $\mathrm{mg} / \mathrm{l}$ and $\mathrm{g} / \mathrm{dl}$, respectively). The minimum detectable concentrations for hsCRP and calprotectin were $0.02 \mathrm{mg} / \mathrm{l}$ and $1.6 \mathrm{ng} / \mathrm{ml}$, respectively. Ischemia modified albumin was measured with the albumin cobalt binding colorimetric assay as described by Bar-Or et al. [36] and the results were given in absorbance units (ABSU). To eliminate the effect of albumin and obtain corrected IMA values, the formula (individual serum albumin concentration/median serum albumin concentration of the population) $\times$ IMA ABSU value was used [37]

\section{Statistical analysis}

Statistical analysis was performed with the Statistical Package for Social Sciences (SPSS) program version 11.0 for Windows (SPSS Inc., Chicago, IL). Conformity to normal distribution of the variables was investigated using visual and analytical methods. Normally distributed continuous values were expressed as mean \pm standard deviation (SD) and categorical variables as number $(n)$ and percentage (\%). Parameters which were not normally distributed were stated as median values with interquartile range (IQR). Continuous parameters were analyzed using the Mann-Whitney $U$ test or the Kruskal-Wallis test. Correlations between numerical data were evaluated with Spearman's correlation coefficient. A value of $p<0.05$ was considered statistically significant.

\section{Results}

There was no statistically significant difference between the groups in respect of age and gender distributions (all $p>0.05)$. Of the patients with BD, 57 (61.3\%) had active disease and 36 (38.7\%) had inactive disease. The demographic characteristics and clinical features of the patients are presented in Table 1. The serum levels of calprotectin, IMA, and hsCRP in patients with $\mathrm{BD}$ were significantly higher than those in the healthy control group (Table 2). When disease activity was assessed with the BDCAF, both active and inactive patients were determined to have significantly higher levels of calprotectin, IMA and hsCRP than the healthy control group (Table 3). Although patients with active disease tended to have higher levels of calprotectin, IMA and hsCRP than those with inactive disease, the difference was statistically significant only for hsCRP (Table 3). No correlation was determined between the calprotectin levels and IMA, hsCRP, ESR, CRP, or BDCAF score. There was also no correlation between the BDCAF score and IMA or hSCRP. 


\section{Discussion}

The results of this study demonstrated that serum levels of calprotectin, IMA and hsCRP were increased in patients with BD compared with the healthy control group. Although patients with active disease had higher average levels of calprotectin, IMA and hsCRP than those with inactive BD, only the difference in hsCRP level was statistically significant. Furthermore, there was no correlation between calprotectin level and IMA, hSCRP, ESR, CRP or the disease activity score.

Similar to the findings of the present study, Oktayoglu et al. observed increased serum concentrations of calprotectin in patients with BD and no correlation between serum levels of calprotectin, CRP, ESR or BDCAF score [23].

Calprotectin plays a crucial role as a significant marker of inflammation in various rheumatological diseases [13]. Viemann et al. reported expression of MRP8/MRP14 in affected vessels and deposition on the endothelial surface of the vessels. With treatment of vasculitis, the level of calprotectin decreases, so it is thought to play a functional role in systemic vasculitis [38]. Hirono et al. observed that elevated serum levels of MRP8/14 in patients with Kawasaki disease were correlated with disease activity and might be a predictor of response to IVIG treatment [39]. Behçet's disease is a complex inflammatory disorder and a well-known vasculitis syndrome. In the current study, serum levels of calprotectin were observed to be significantly higher in patients with BD than in the healthy control group.

Kim et al. analyzed the fecal calprotectin level of patients with intestinal BD, and found that the calprotectin level was significantly higher in BD patients with intestinal involvement than in those without intestinal involvement, and a higher fecal calprotectin level was significantly associated with intestinal BD with typical ulceration [40]. In the current study, increased levels of calprotectin were also observed.

Oxidative stress is a key factor in vascular injury. Ischemia modified albumin is a systemic biomarker of oxidative stress and has recently been extensively investigated [41]. Elevated serum levels of IMA in patients with BD have been demonstrated in previous studies [28, 29]. Bekpinar et al. observed that oxidative stress may occur during the active stage of BD caused by inflammatory conditions [42]. Buldanlioglu et al. demonstrated that in BD, the antioxi-

Table 1. Demographic characteristics and clinical features of patients with $\mathrm{BD}$

\begin{tabular}{lc}
\hline Parameter & Value \\
\hline Age, mean \pm SD [years] & $38.3 \pm 8.4$ \\
\hline Age at diagnosis, mean \pm SD [years] & $30.4 \pm 7.6$ \\
\hline Disease duration, median (IQR) [months] & $96.3(74.1)$ \\
\hline Female/male, $n(\%)$ & $36(38.7) /$ \\
\hline Active disease, $n(\%)$ & $57(61.3)$ \\
\hline BDCAF, median (IQR) & $57(61.3)$ \\
\hline
\end{tabular}

Disease manifestations ever presented by BD patients, $n(\%)$ :

\begin{tabular}{lc}
\hline Oral ulcers & $93(100)$ \\
\hline Genital ulcers & $72(77.4)$ \\
\hline Erythema nodosum & $42(45.2)$ \\
\hline Papulopustular lesions & $55(59.1)$ \\
\hline Positivity of pathergy test & $20(21.5)$ \\
\hline Arthritis & $37(39.8)$ \\
\hline Uveitis & $35(37.6)$ \\
\hline Vascular involvement & $31(33.3)$ \\
\hline Gastrointestinal system involvement & $1(1.1)$ \\
\hline Central nervous system involvement & $\begin{array}{c}\text { Parenchymal 7 (7.5) } \\
\text { Cerebral venous } \\
\text { sinus thrombosis } \\
(1.1)\end{array}$ \\
\hline Pulmonary aneurysm & $2(2.2)$
\end{tabular}

Medical therapy, $n$ (\%):

\begin{tabular}{lc}
\hline Colchicine & $71(66)$ \\
\hline Azathioprine & $47(50.5)$ \\
\hline Cyclophosphamide & $3(3.2)$ \\
\hline Corticosteroids & $50(53.8)$ \\
\hline Interferon & $1(1.1)$ \\
\hline Anti-TNF & $1(1.1)$ \\
\hline No therapy & $4(3.7)$ \\
\hline
\end{tabular}

Table 2. Serum levels of calprotectin, IMA and hsCRP of patients with BD and healthy control subjects

\begin{tabular}{lccc}
\hline Parameter & Patients with BD & Healthy control group & $P$-value \\
\hline IMA & $0.55(0.49-0.60)$ & $0.46(0.40-0.51)$ & $<0.0001$ \\
\hline hsCRP & $6.33(3.10-12.80)$ & $1.45(0.80-2.12)$ & $<0.0001$ \\
\hline Calprotectin & $4807.50(4062.0-5861.75)$ & $3079.50(2255.25-3861.50)$ & $<0.0001$ \\
\hline
\end{tabular}

All values are stated as median (IQR). IMA - ischemia modified albumin, hSCRP - high-sensitivity C-reactive protein. 
Table 3. Serum levels of calprotectin, IMA and hsCRP according to disease activity in patients with BD

\begin{tabular}{|c|c|c|c|c|c|c|c|}
\hline Parameter & $\begin{array}{l}\text { Patients with } \\
\text { inactive disease } \\
(n=36)\end{array}$ & $\begin{array}{l}\text { Patients with active } \\
\text { disease }(n=57)\end{array}$ & $\begin{array}{l}\text { Healthy control } \\
\text { group }(n=62)\end{array}$ & $P$-value & $P$-value* & $P$-value** & $P$-value ${ }^{\star * *}$ \\
\hline CRP & $2(1-5.25)$ & $7(2-13.5)$ & - & - & $<0.0001$ & - & - \\
\hline ESR & $6(3-12.25)$ & $8(3-14.50)$ & - & - & 0.481 & - & - \\
\hline IMA & $0.55(0.49-0.59)$ & $0.55(0.49-0.61)$ & $0.46(0.40-0.51)$ & $<0.0001$ & 0.586 & $<0.0001$ & $<0.0001$ \\
\hline hsCRP & $4.03(2.14-7.27)$ & $7.60(4.75-15.86)$ & $1.45(0.80-2.12)$ & $<0.0001$ & 0.001 & $<0.0001$ & $<0.0001$ \\
\hline Calprotectin & $\begin{array}{c}4764.00 \\
(3782.25-5586.75)\end{array}$ & $\begin{array}{c}4890.50 \\
(4065.75-6133.00)\end{array}$ & $\begin{array}{c}3079.50 \\
(2255.25-3861.50)\end{array}$ & $<0.0001$ & 0.268 & $<0.0001$ & $<0.0001$ \\
\hline
\end{tabular}

All values are stated as median (IQR). *Difference between active and inactive patients, **difference between inactive patients and healthy control group, *** difference between active patients and healthy control group. CRP - C-reactive protein, ESR-erythrocyte sedimentation rate, IMA - ischemia modified albumin, hSCRP - high-sensitivity C-reactive protein.

dant system is deficient and inadequate, especially in patients in the active stage of the disease [43].

In contrast to the current study, Ozyazgan et al. found that IMA levels were significantly increased in patients with active periods of BD compared with the healthy control group and patients in remission periods of BD [30]. Çapkın et al. observed that BD patients with vascular involvement had significantly higher IMA levels than BD patients without vascular involvement [31].

Behçet's disease is characterized by recurrent attacks and remission. Currently there are no laboratory markers that correlate well with the clinical activity of BD [44].

This study can be accepted as a pioneer study as it focuses on IMA, calprotectin and hsCRP as different biomarkers of inflammation and oxidative stress in patients with BD.

The major limitation of this study was the cross-sectional design. No definitive conclusion could be drawn about the actual relationship between the changes in serum calprotectin levels and changes in disease activity or specific organ involvement in BD. The data were obtained from a single center only, and therefore patient selection bias was not completely avoided. At the time of the sample collection, all the patients were already taking corticosteroids and immunosuppressive agents, which might have affected the calprotectin levels.

\section{Conclusions}

Increased serum levels of calprotectin in patients with BD strengthen the possibility that calprotectin plays a role in the pathogenesis of $\mathrm{BD}$. There is a need for further, prospective, large scale, longitudinal studies to investigate serum calprotectin levels in conjunction with disease activity, specific organ involvement and treatment response.

\section{Conflict of interest}

The authors declare no conflict of interest.

\section{References}

1. Hatemi G, Yazici Y, Yazici H. Behcet's syndrome. Rheum Dis Clin North Am 2013; 39: 245-61.

2. Alpsoy E. Behcet's disease: a comprehensive review with a focus on epidemiology, etiology and clinical features, and management of mucocutaneous lesions. J Dermatol 2016; 43: 620-32.

3. Pineton de Chambrun M, Wechsler B, Geri G, et al. New insights into the pathogenesis of Behcet's disease. Autoimmun Rev 2012; 11: 687-98.

4. Mendoza-Pinto C, García-Carrasco M, Jiménez-Hernán$\operatorname{dez} \mathrm{M}$, et al. Etiopathogenesis of Behcet's disease. Autoimmun Rev 2012; 9: 241-45.

5. Jiang Y, Zang M, Li S. Serum PLR and LMR in Behcet's disease: Can they show the disease activity? Medicine (Baltimore) 2017; 96: e6981.

6. Park JS, Kang MI, Ha YJ, et al. Serum anti-lysozyme is associated with disease activity of Behcet's disease. Int J Rheum Dis 2017; 20: 261-8.

7. Balta I, Balta S, Koryurek OM, et al. Serum endocan levels as a marker of disease activity in patients with Behcet disease. J Am Acad Dermatol 2014; 70: 291-6.

8. Sarıyıldız MA, Yazmalar L, Batmaz i, et al. Serum GDF-15 level in Behcet's disease: relationships between disease activity and clinical parameters. Int I Dermatol 2016; 55: 1289-94.

9. Yazmalar L, Batmaz i, Sula B, et al. Serum levels of alpha-1 acid glycoprotein and pentraxin 3 in patients with Behcet's disease and relationship with disease activity. Int I Dermatol 2015; 54: e394-400.

10. Durmazlar SP, Ulkar GB, Eskioglu F, et al. Significance of serum interleukin-8 levels in patients with Behcet's disease: high levels may indicate vascular involvement. Int J Dermatol 2009; 48: 259-64.

11. Adam B, Calikoglu E. Serum interleukin-6, procalcitonin and C-reactive protein levels in subjects with active Behcet's disease. J Eur Acad Dermatol Venereol 2004; 18: 318-20.

12. Cantarini L, Pucino V, Vitale A, et al. Immunometabolic biomarkers of inflammation in Behcet's disease: relationship with epidemiological profile, disease activity and therapeutic regimens. Clin Exp Immunol 2016; 184: 197-207.

13. Kopec-Medrek M, Widuchowska M, Kucharz EJ. Calprotectin in rheumatic diseases: a review. Reumatologia 2016; 54 : 306-9.

14. Pruenster M, Vogl T, Roth J, et al. S100A8/A9: from basic science to clinical application. Pharmacol Ther 2016; 167: 120-31. 
15. Ometto F, Friso L, Astorri D, et al. Calprotectin in rheumatic diseases. Exp Biol Med (Maywood) 2017; 242: 859-73.

16. Abildtrup M, Kingsley GH, Scott DL. Calprotectin as a biomarker for rheumatoid arthritis: a systematic review. J Rheumatol 2015; 42: 760-70.

17. Guo Q, Zha X, Li C, et al. Serum calprotectin-a promising diagnostic marker for adult-onset Still's disease. Clin Rheumatol 2016; 35: 73-9.

18. Reveille JD. Biomarkers for diagnosis, monitoring of progression, and treatment responses in ankylosing spondylitis and axial spondyloarthritis. Clin Rheumatol 2015; 34: 1009-18.

19. Inciarte-Mundo J, Ramirez J, Hernandez MV, et al. Calprotectin and TNF trough serum levels identify power Doppler ultrasound synovitis in rheumatoid arthritis and psoriatic arthritis patients in remission or with low disease activity. Arthritis Res Ther 2016; 18: 160.

20. Nordal HH, Brun JG, Halse AK, et al. Calprotectin (S100A8/A9), S100A12, and EDTA-resistant S100A12 complexes (ERAC) in primary Sjogren's syndrome. Scand I Rheumatol 2014; 43: 76-8.

21. Haga HJ, Brun JG, Berntzen HB, et al. Calprotectin in patients with systemic lupus erythematosus: relation to clinical and laboratory parameters of disease activity. Lupus 1993; 2: 47-50.

22. Mariani A, Marsili M, Nozzi M, et al. Serum calprotectin: review of its usefulness and validity in paediatric rheumatic diseases. Clin Exp Rheumatol 2015; 33: 109-14.

23. Oktayoglu P, Mete N, Caglayan M, et al. Elevated serum levels of calprotectin (MRP8/MRP14) in patients with Behcet's disease and its association with disease activity and quality of life. Scand J Clin Lab Invest 2015; 75: 106-12.

24. Lippi G, Montagnana M, Guidi GC. Albumin cobalt binding and ischemia modified albumin generation: an endogenous response to ischemia? Int J Cardiol 2006; 108: 410-1.

25. Collinson PO, Gaze DC. Ischaemia-modified albumin: clinical utility and pitfalls in measurement. J Clin Pathol 2008; 61: 1025-8.

26. Guntas G, Sahin A, Duran S, et al. Evaluation of ischemiamodified albumin in patients with inflammatory bowel disease. Clin Lab 2017; 63: 341-7.

27. Kucuk A, Uslu AU, Arslan S, et al. Ischemia-modified albumin and atherosclerosis in patients with familial mediterranean fever. Angiology 2016; 67: 456-60.

28. Leitemperguer MR, Tatsch E, Kober H, et al. Assessment of ischemia-modified albumin levels in patients with rheumatoid arthritis. Clin Lab 2014; 60: 1065-70.

29. Ozdemir M, Kiyici A, Balevi A, et al. Assessment of ischaemia-modified albumin level in patients with psoriasis. Clin Exp Dermatol 2012; 37: 610-4.

30. Ozyazgan S, Andican G, Erman H, et al. Relation of protein oxidation parameters and disease activity in patients with Behcet's disease. Clin Lab 2013; 59: 819-25.

31. Capkin E, Karkucak M, Kola M, et al. Ischemia-modified albumin (IMA): a novel marker of vascular involvement in Behcet's disease? Joint Bone Spine 2015; 82: 68-9.

32. Kilic S, Isik S, Hiz MM, et al. The ischemia modified albumin and mean platelet volume levels in patients with Behcet's disease. Adv Dermatol Allergol 2016; 33: 345-8.

33. International Study Group for Behcet's Disease. Criteria for diagnosis of Behcet's disease. Lancet 1990; 335: 1078-80.

34. Hamuryudan V, Fresko I, Direskeneli H, et al. Evaluation of the Turkish translation of a disease activity form for Behcet's syndrome. Rheumatology (Oxford) 1999; 38: 734-6.

35. Bhakta BB, Brennan P, James TE, et al. Behcet's disease: evaluation of a new instrument to measure clinical activity. Rheumatology (Oxford) 1999; 38: 728-33.
36. Bar-Or D, Lau E, Winkler JV. A novel assay for cobalt-albumin binding and its potential as a marker for myocardial ischemia - a preliminary report. J Emerg Med 2000; 19: 311-5.

37. Sbarouni E, Georgiadou P, Voudris V. Ischemia modified albumin changes - review and clinical implications. Clin Chem Lab Med 2011; 49: 177-84.

38. Viemann D, Strey A, Janning A, et al. Myeloid-related proteins 8 and 14 induce a specific inflammatory response in human microvascular endothelial cells. Blood 2000; 105: 2955-62.

39. Hirono K, Foell D, Xing Y, et al. Expression of myeloid-related protein-8 and -14 in patients with acute Kawasaki disease. J Am Coll Cardiol 2006; 48: 1257-64.

40. Kim DH, Park Y, Kim B, et al. Fecal calprotectin as a noninvasive biomarker for intestinal involvement of Behçet's disease. J Gastroenterol Hepatol 2017; 32: 595-601.

41. Balta S, Aparci M, Demir M, et al. Ischemia-modified albumin in patients with seizure. Am J Emerg Med 2014; 32: 1282.

42. Bekpinar S, Kiliç N, Unlüçerçi Y, et al. Evaluation of nitrosative and oxidative stress in Behçet disease. J Eur Acad Dermatol Venereol 2005; 19: 167-71.

43. Buldanlioglu S, Turkmen S, Ayabakan HB, et al. Nitric oxide, lipid peroxidation and antioxidant defence system in patients with active or inactive Behçet's disease. Br J Dermatol 2005; 153: 526-30.

44. Shahram F, Khabbazi A, Nadji A, et al. Comparison of existing disease activity indices in the follow-up of patients with Behcet's disease. Mod Rheumatol 2009; 19: 536-41. 